\title{
Efficacy and safety profile of combination of
} tramadol-diclofenac versus tramadol-paracetamol in patients with acute musculoskeletal conditions, postoperative pain, and acute flare of osteoarthritis and rheumatoid arthritis: a Phase III, 5-day open-label study

\author{
This article was published in the following Dove Press journal: \\ Journal of Pain Research \\ 12 August 2014 \\ Number of times this article has been viewed
}

\author{
Ajay S Chandanwale' \\ Subramanian Sundar ${ }^{2}$ \\ Kaliaperumal \\ Latchoumibady ${ }^{3}$ \\ Swati Biswas ${ }^{4}$ \\ Mukesh Gabhane ${ }^{4}$ \\ Manoj Naik ${ }^{5}$ \\ Kamlesh Patel ${ }^{4}$ \\ 'Department of Orthopedics \& \\ Traumatology, Byramjee Jeejeebhoy \\ Medical College and Sassoon General \\ Hospital, Pune, Maharashtra, India; \\ ${ }^{2}$ Vasantha Subramanian Hospital, \\ Chennai, Tamil Nadu, India; ${ }^{3}$ Vijay \\ Hospital, Pondicherry, India; ${ }^{4}$ Medical \\ Services Department, ${ }^{5}$ Clinical \\ Research Department, Abbott \\ Healthcare Pvt Ltd, Mumbai, India
}

Objective: We aimed to evaluate the safety and efficacy of a fixed-dose combination (FDC) of tramadol and diclofenac versus a standard approved FDC of tramadol and paracetamol, in patients with acute moderate to severe pain.

Methods: A total of 204 patients with moderate to severe pain due to acute musculoskeletal conditions ( $n=52)$, acute flare of osteoarthritis $(n=52)$, acute flare of rheumatoid arthritis $(n=50)$, or postoperative pain $(n=50)$ were enrolled in the study at baseline. Each disease category was then randomized to receive either of two treatments for 5 days: group A received an FDC of immediate-release tramadol hydrochloride $(50 \mathrm{mg})$ and sustained-release diclofenac sodium (75 mg) (one tablet, twice daily), and group B received an FDC of tramadol hydrochloride $(37.5 \mathrm{mg}$ ) and paracetamol (325 mg) (two tablets every 4-6 hours, up to a maximum of eight tablets daily). The primary efficacy end points were reductions in pain intensity from baseline at day 3 and day 5 as assessed by a Visual Analog Scale (VAS) score.

Results: Group A showed a significant reduction in the VAS score for overall pain from baseline on day $3(P=0.001)$ and day $5(P<0.0001)$ as compared with group B. The combination of tramadol-diclofenac resulted in few mild to moderate adverse events (nausea, vomiting, epigastric pain, and gastritis), which required minimal management, without any treatment discontinuation. The number of adverse events in group A was nine (8.82\%) compared with 22 $(21.78 \%)$ in group B, after 5 days of treatment.

Conclusion: An FDC of tramadol-diclofenac showed a significantly greater reduction in pain intensity and was well tolerated compared with tramadol-paracetamol, resulting in better analgesia in patients suffering from moderate to severe pain due to acute musculoskeletal conditions, postoperative pain following orthopedic surgery, or acute flare of osteoarthritis and rheumatoid arthritis.

Keywords: tramadol and diclofenac combination, moderate to severe pain

\section{Introduction}

According to the 1995 Support study, approximately half of patients with any medical condition present with pain. ${ }^{1}$ Pain remains the most inadequately treated symptom, due to different cultural, attitudinal, educational, legal, and system-related reasons. 
Pain has a multifactorial origin, hence it may be difficult to achieve effective pain control with a single drug. ${ }^{2}$ Combination therapy of analgesics from different groups is advantageous in targeting both peripheral and central pain pathways and hence, helps in production of analgesia at lower and more tolerable doses of the constituent drugs. ${ }^{3,4}$ Combination therapies can have a positive influence on the ability of individual components to minimize pain, with better tolerability and reduced recovery time. ${ }^{4}$

The World Health Organization (WHO) Analgesic Ladder proposed in 1986 needs revision in the form of customized and patient-centric management of pain. According to the WHO ladder, the combination of paracetamol or nonsteroidal anti-inflammatory drugs (NSAIDs) with opioids was considered as the second step in the treatment of pain, based on increasing pain severity. ${ }^{5}$ Now, instead of a ladder, a platform is the need of the hour, as different levels of pain severity and chronicity demand different analgesic platforms of management. Now, the clinician should be able to move up or down the appropriate platform to explore the various treatment options according to the status and needs of the individual patient. ${ }^{6}$

The pharmacologic treatment of pain due to rheumatologic conditions, especially osteoarthritis, has many limitations, in terms of serious adverse effects and low efficacy. Lower doses of paracetamol represent an analgesic option for many patients, especially the elderly. However, historical data demonstrates hepatotoxicity at paracetamol doses greater than the maximum daily recommended dose of $4 \mathrm{gm} /$ day. Data also suggest that paracetamol, at high doses, may add to the risk of upper gastrointestinal (GI) complications. Opioids may exhibit abuse potential, along with limited efficacy, over time. NSAIDs present a significant GI bleeding risk, along with a risk of a variety of renal complications, and myocardial infarction and other serious cardiovascular complications. ${ }^{7}$ In addition, NSAIDs also have ceiling effects, and no therapeutic advantage is gained after increasing dosages beyond those recommended. ${ }^{8}$ If the therapeutic advantage of NSAIDs needs to be utilized, then one of the options is to prescribe NSAIDs as a combination therapy. NSAIDs are one of the mainstay treatment options for musculoskeletal pain of moderate intensity. The recent guidelines issued by numerous professional medical societies, recommend NSAIDs at the lowest effective dose and shortest possible period, in view of the associated gastrointestinal, renal, and cardiovascular toxicity. ${ }^{9}$

Opioids, which have a dual mode of action on opioid and monoaminergic receptors, comprise another group of analgesic drugs that are efficacious against both nociceptive and neuropathic pain. Among the opioids, tramadol has fewer side effects, such as constipation, respiratory depression, and sedation, compared with the typical strong opioids. Tramadol is now considered to be a first-line analgesic for many musculoskeletal indications. ${ }^{9}$

The general recommendation for the management of moderate to severe acute pain is a combination of paracetamol or NSAIDs with opioids, based on increasing pain severity. This combination has an advantage of additive analgesic effects along with a minimized dose of opioids and hence, minimal undesirable side effects. NSAIDs offer an opioidsparing strategy in which the opioid activity can be potentiated by NSAIDs. This activity is due to an increased conversion of arachidonic acid to 12-lipoxygenase products, which in turn augments the effects of opioids on $\mathrm{K}^{+}$channels. ${ }^{10}$

The fixed-dose combination (FDC) of tramadol and paracetamol has been extensively evaluated and compared with other combinations. Results from preclinical studies have observed both the dual mechanism of action of tramadol and the analgesic synergy between the two compounds in this FDC. ${ }^{11}$ According to a meta-analysis, the combination of tramadol and acetaminophen was more effective than either of its two components administered alone, with an almost similar safety profile to either of the components prescribed alone. ${ }^{12}$

The diverse mechanisms of action of diclofenac include inhibition of the thromboxane-prostanoid receptor, effect on arachidonic acid release and uptake, inhibition of lipoxygenase enzymes, and activation of the nitric oxide-cyclic guanosine monophosphate (cGMP) antinociceptive pathway. ${ }^{13}$ On the other hand, tramadol is an atypical, centrally acting analgesic, as a result of its combined effect as opioid agonist and serotonin and noradrenaline reuptake inhibitor. ${ }^{14,15}$ Theoretically, the combination of tramadol hydrochloride (immediate release) and diclofenac sodium (sustained release) should provide both immediate and a long-term pain relief. But there is not enough literature on the benefits of this combination, and hence, a multicenter Phase III clinical trial was conducted across three centers in India to compare the efficacy and safety of the FDC of immediate-release tramadol $50 \mathrm{mg}$ and sustained-release diclofenac $75 \mathrm{mg}$ compared with an approved FDC of tramadol $37.5 \mathrm{mg}$ and paracetamol $325 \mathrm{mg}$, in the treatment of patients with moderate to severe pain characterized as acute musculoskeletal pain (AMSP), postoperative pain (POP), acute flare of osteoarthritis (AFOA), or acute flare of rheumatoid arthritis (AFRA). 


\section{Materials and methods}

The study was a 5-day randomized, open-label, comparative, parallel group, multicenter trial conducted at three centers in India. A total of 204 patients, both males and females between 18-70 years of age, with moderate to severe pain at baseline (Visual Analog Scale [VAS] score ${ }^{16}>50 \mathrm{~mm}$ during the 5 days prior to the baseline visit) and diagnosed with AMSP (tendonitis, bursitis, synovitis), AFOA, AFRA, or POP were included in the study. Although rheumatoid arthritis and osteoarthritis are chronic diseases, patients often experience acute episodes of pain and inflammation, known as flare-up. Patients on any other treatment medications (including NSAIDs, corticosteroids, and opioid analgesics) or alternate therapy (including physiotherapy and acupuncture) were excluded from the study.

The study population was categorized depending upon the disease, as: AMSP, AFOA, AFRA, and POP. Patients in each category were randomized into two groups. Group A received an FDC of immediate-release tramadol $50 \mathrm{mg}$ and sustained-release diclofenac $75 \mathrm{mg}$ twice a day (12-hourly) for 5 days. This dose was based on the recommendation for combining the NSAID (diclofenac) at the recommended therapeutic dose (ie, $150 \mathrm{mg} /$ day) with the minimal acceptable dose of Tramadol (ie, $100 \mathrm{mg}$ /day), taking advantage of the opioid-sparing effect of the NSAIDs. Group B received an FDC of tramadol $37.5 \mathrm{mg}$ and paracetamol $325 \mathrm{mg}$, two tablets every 4 to 6 hours, up to a maximum of eight tablets daily, as per the usual prescribed dosage of the FDC.

Patients from all the disease categories were assessed, at baseline and subsequently on day 3 and day 5 of treatment, on the following parameters: pain intensity, pain relief, swelling, inflammation, disability, and use of rescue medications. The primary efficacy parameter was reduction in pain intensity. The pain intensity was measured with a 0-100 mm VAS scale (for overall pain, pain at rest, and pain on movement). Pain relief was measured at the end of the 5-day treatment.

In addition to this, assessment for the Western Ontario and McMaster University Scale (WOMAC) index ${ }^{17}$ was done to assess the pain, stiffness, and physical function in patients with AFOA; the Health Assessment Questionnaire (HAQ) scale ${ }^{18}$ was done to assess the quality of life in patients with AFRA; and the Numerical Rating Scale $(\mathrm{NRS})^{16}$ was done in patients with POP. The NRS score was evaluated on a six-point rating scale $(0=$ no hurt and $5=$ worst) (the higher the score, the worse the pain) at intervals of $0.5,1,2,4,8,16$, and 24 hours from the time of administration of the medication, in patients with POP.
A global assessment of efficacy and tolerability was done at the end of the study. Unbearable pain during the study period was treated with rescue medication (diclofenac), and the number of tablets of rescue medication was noted at each visit.

The safety profile was assessed by capturing the adverse events (AEs), and with biochemical laboratory investigations (serum glutamic oxaloacetic transaminase [SGOT], serum glutamic pyruvic transaminase [SGPT], alkaline phosphatase, and serum creatinine) and hematological investigation (hemoglobin, total red blood cells, total white blood cells, neutrophils, lymphocytes, eosinophils, and basophils). Tolerability was assessed on a three-point scale, as good (side effects mild or not observed), moderate (side effects of moderate intensity), or poor (side effects severe or discontinuation).

The study protocol and informed consent were approved by the ethics committees of Grant Medical College and Sir Jamshedjee Jeejebhoy Group of Hospitals, Mumbai; Vasantha Subramanian Hospital, Chennai; and Vijay Hospital, Pondicherry, India. The patients reviewed and voluntarily signed the informed consent form prior to involvement in any study-related activity.

The data was analyzed after pooling from all the centers. The two treatment groups were evaluated for baseline comparability of demographic data and baseline scores for symptoms. The efficacy analysis was done with per-protocol analysis, and safety analysis was done using intent-to-treat analysis. Quantitative data was analyzed by assessing Student's $t$-test and analysis of variance (ANOVA), and ranking/ qualitative data were analyzed using Mann-Whitney $U$ test and the Kruskall-Wallis test. Proportions were compared using the chi-square test. The significance level was $P<0.05$ for all the statistical tests.

\section{Results}

A total of 204 patients were enrolled, out of whom 203 completed the study. There were 51 patients with AMSP, 52 patients with AFOA, and 50 patients each with AFRA and POP. There was a male preponderance in the study $(61 \%$ male versus 39\% female). The age, pulse rate, temperature, and systolic and diastolic blood pressures were comparable in both the treatment groups (Table 1).

The analysis of the study was performed separately for the four pain conditions, AMSP, AFOA, AFRA, and POP, as well as for the whole population (pooled data). The reduction in the intensity for overall pain was assessed with the VAS score, and the scores for the subgroups were 
Table I Demographic details of the study population $(n=203)$

\begin{tabular}{|c|c|c|}
\hline Parameters & $\begin{array}{l}\text { Tramadol + } \\
\text { diclofenac } \\
(n=102)\end{array}$ & $\begin{array}{l}\text { Tramadol + } \\
\text { paracetamol } \\
(n=\mid 0 I)\end{array}$ \\
\hline Age, years & $50.80(11.30)$ & $51.14(11.43)$ \\
\hline \multicolumn{3}{|l|}{ Sex } \\
\hline Male, number (\%) & $63(61.76 \%)$ & $60(59.41 \%)$ \\
\hline Female, number (\%) & 39 (38.24\%) & $4 \mathrm{I}(40.59 \%)$ \\
\hline \multicolumn{3}{|l|}{ Vital signs } \\
\hline Pulse, per min & $78.52(6.98)$ & $77.24(6.17)$ \\
\hline Temperature, ${ }^{\circ} \mathrm{C}$ & $5 I .95(26.4 I)$ & $52.35(26.72)$ \\
\hline Systolic BP, mmHg & I 19.49 (I I.86) & II 8.50 (12.77) \\
\hline Diastolic BP, mmHg & $81.78(6.76)$ & $80.44(7.30)$ \\
\hline
\end{tabular}

Note: Values are expressed as mean (SEM), unless otherwise indicated. Abbreviations: BP, blood pressure; SEM, standard error of the mean.

compared for treatment, in group A and B. In both the AMSP and AFOA groups, there was no significant decrease in mean change and percentage change from baseline in overall pain score on day 3 . However, on day 5 , significant reduction was observed in the mean change and percentage change in the overall pain score from baseline $(P=0.002$ and $P=0.01$, respectively). In case of the AFRA subgroup,

Table 2 Mean score for overall pain on the 0-100 mm VAS scale, in four subpopulation groups

\begin{tabular}{|c|c|c|c|}
\hline VAS score & $\begin{array}{l}\text { Tramadol + } \\
\text { diclofenac } \\
(n=\mid 02)\end{array}$ & $\begin{array}{l}\text { Tramadol + } \\
\text { paracetamol } \\
(n=101)\end{array}$ & $P$-value \\
\hline \multicolumn{4}{|l|}{ AMSP } \\
\hline Baseline, mean (SEM) & $70.38(2.74)$ & $68.20(2.63)$ & 0.568 \\
\hline $\begin{array}{l}\text { Day } 3 \text {, mean change } \\
\text { (\% change) }\end{array}$ & $-3 I .54(-44.8 I)$ & $-22.56(-33.08)$ & 0.233 \\
\hline $\begin{array}{l}\text { Day } 5 \text {, mean change } \\
\text { (\% change) }\end{array}$ & $-48.46(-68.85)$ & $-30.44(-44.63)$ & 0.002 \\
\hline \multicolumn{4}{|l|}{ AFOA } \\
\hline Baseline, mean (SEM) & $70.74(2.57)$ & $74.00(1.63)$ & 0.298 \\
\hline $\begin{array}{l}\text { Day } 3 \text {, mean change } \\
\text { (\% change) }\end{array}$ & $-34.56(-48.85)$ & $-30.40(-41.08)$ & 0.340 \\
\hline $\begin{array}{l}\text { Day } 5 \text {, mean change } \\
\text { (\% change) }\end{array}$ & $-50.00(-70.68)$ & $-37.28(-50.38)$ & 0.01 \\
\hline \multicolumn{4}{|l|}{ AFRA } \\
\hline Baseline, mean (SEM) & $75.42(2.33)$ & $78.85(1.15)$ & 0.183 \\
\hline $\begin{array}{l}\text { Day } 3 \text {, mean change } \\
\text { (\% change) }\end{array}$ & $-39.25(-52.04)$ & $-25.81(-32.73)$ & 0.036 \\
\hline $\begin{array}{l}\text { Day } 5 \text {, mean change } \\
\text { (\% change) }\end{array}$ & $-55.92(-74.14)$ & $-38.42(-48.73)$ & 0.001 \\
\hline \multicolumn{4}{|l|}{ POP } \\
\hline Baseline, mean (SEM) & $72.40(3.02)$ & $81.20(1.45)$ & 0.011 \\
\hline $\begin{array}{l}\text { Day } 3 \text {, mean change } \\
\text { (\% change) }\end{array}$ & $-16.40(22.65)$ & $-11.20(13.79)$ & $<0.000$ I \\
\hline $\begin{array}{l}\text { Day } 5 \text {, mean change } \\
\text { (\% change) }\end{array}$ & $-4 I .60(57.46)$ & $-23.60(29.06)$ & $<0.0001$ \\
\hline
\end{tabular}

Abbreviations: AFOA, acute flare of osteoarthritis; AFRA, acute flare of rheumatoid arthritis; AMSP, acute musculoskeletal pain; POP, postoperative pain; SEM, standard error of the mean; VAS, Visual Analog Scale. there was significantly greater reduction seen in the mean change and percentage change from baseline in the overall pain score on day $3(P=0.036)$ and day $5(P=0.001)$. Similarly, in the POP subgroup, the mean change and percentage change from baseline in overall pain score was significantly reduced both on day 3 and day $5(P<0.0001)$ as shown in Table 2.

The other parameters used for pain assessment were the WOMAC index score in the AFOA group, total HAQ score in AFRA group, and the NRS scale assessment for the POP group (Table 3), and the scores in each subgroup were compared between treatment groups $\mathrm{A}$ and $\mathrm{B}$. The WOMAC score, in AFOA, was reduced significantly after day $3(P=0.04)$ and day $5(P<0.007)$. Similarly, the total HAQ score in the AFRA group also significantly decreased after treatment on both days $(P=0.325$ and $P=0.003$ on day

Table 3 Comparison of efficacy parameters between group $A$ (tramadol + diclofenac) and group B (tramadol + paracetamol) of the study population

\begin{tabular}{|c|c|c|c|}
\hline Efficacy parameters & $\begin{array}{l}\text { Group A: } \\
\text { Tramadol + } \\
\text { diclofenac } \\
(n=102)\end{array}$ & $\begin{array}{l}\text { Group B: } \\
\text { Tramadol + } \\
\text { paracetamol } \\
(n=\mid 0 I)\end{array}$ & $P$-value \\
\hline \multicolumn{4}{|c|}{ WOMAC index score in AFOA } \\
\hline Baseline, mean (SEM) & $47.88(3.8 I)$ & $44.08(3.58)$ & 0.471 \\
\hline $\begin{array}{l}\text { Day } 3 \text {, mean change } \\
\text { (\% change) }\end{array}$ & $-23.00(-48.02)$ & $-11.76(-26.68)$ & 0.04 \\
\hline $\begin{array}{l}\text { Day } 5, \text { mean change } \\
\text { (\% change) }\end{array}$ & $-32.08(-66.99)$ & $-18.80(-42.65)$ & 0.007 \\
\hline \multicolumn{4}{|c|}{ Total HAQ score in AFRA } \\
\hline Baseline, mean (SEM) & $39.08(3.07)$ & $33.42(3.4 I)$ & 0.226 \\
\hline $\begin{array}{l}\text { Day } 3 \text {, mean change } \\
\text { (\% change) }\end{array}$ & $-16.17(-41.36)$ & $-6.54(-19.58)$ & 0.325 \\
\hline $\begin{array}{l}\text { Day } 5 \text {, mean change } \\
\text { (\% change) }\end{array}$ & $-28.92(-73.99)$ & $-\mid 3.78(-4 \mid .24)$ & 0.003 \\
\hline \multicolumn{4}{|c|}{ Total HAQ score for pain in AFRA } \\
\hline Baseline, mean (SEM) & $74.48(4.12)$ & $78.26(1.82)$ & 0.391 \\
\hline $\begin{array}{l}\text { Day } 3 \text {, mean change } \\
\text { (\% change) }\end{array}$ & $-28.52(-38.30)$ & $-16.43(-21.00)$ & 0.001 \\
\hline $\begin{array}{l}\text { Day } 5 \text {, mean change } \\
\text { (\% change) }\end{array}$ & $-47.07(-63.20)$ & $-27.57(-35.22)$ & NA \\
\hline \multicolumn{4}{|c|}{ NRS scale assessment for POP } \\
\hline $\begin{array}{l}\text { NRS at } 2 \text { hours, } \\
\text { mean (SEM) }\end{array}$ & $1.25(0.323)$ & $2.13(0.192)$ & 0.028 \\
\hline $\begin{array}{l}\text { NRS at } 4 \text { hours, } \\
\text { mean (SEM) }\end{array}$ & $1.18(0.23 I)$ & $2.44(0.305)$ & 0.002 \\
\hline $\begin{array}{l}\text { NRS at } 8 \text { hours, } \\
\text { mean (SEM) }\end{array}$ & $1.00(0.149)$ & $3.25(0.310)$ & $<0.0001$ \\
\hline $\begin{array}{l}\text { NRS at } 24 \text { hours, } \\
\text { mean (SEM) }\end{array}$ & $0.83(0.167)$ & $3.22(0.435)$ & $<0.0001$ \\
\hline
\end{tabular}

Abbreviations: AFOA, acute flare of osteoarthritis; AFRA, acute flare of rheumatoid arthritis; HAQ, Health Assessment Questionnaire; NA, not applicable; NRS, Numerical Rating Scale; POP, postoperative pain; SEM, standard error of the mean; WOMAC, Western Ontario and McMaster Universities Arthritis Index. 
3 and day 5, respectively). Similarly, in patients with AFRA, assessment of the HAQ subscore for pain, showed a significant reduction $(P=0.001)$. The NRS score for pain intensity in POP also showed a consistent decrease, with a significant reduction appearing as early as 2 hours after the medication was administered. A consistent decrease in the VAS scores was also seen in both the treatment groups, more so in the group A patients (Figure 1).

In the pooled population, the comparison with the mean VAS score from baseline after the 5-day treatment is shown in Table 4, and again the scores were compared between groups A and B. There was significantly greater reduction in the mean change and percentage change from baseline in the overall pain score on day $3(P=0.001)$ and day $5(P<0.0001)$. The VAS score for pain at rest on day 5 also showed a significant reduction in mean and percentage change from baseline $(P<0.0001)$. The VAS score for pain on movement reduced significantly on day $3(P=0.002)$ and day $5(P<0.0001)$.
There was an associated significant reduction in swelling and inflammation scores in group $\mathrm{A}$ as compared with group $\mathrm{B}$ on day $3(P<0.0001)$ and day 5 of therapy $(P<0.0001)$. The mean and percentage change from baseline swelling scores and composite inflammation scores also reduced significantly on day $3(P<0.0001)$ and day $5(P<0.0001)$ in group A as compared to group B.

The amount of rescue medications used, in the form of diclofenac (not more than $150 \mathrm{mg}$ ), was found to be significantly greater in group B (44 tablets) compared with group A (eight tablets) (Table 4).

Compliance was assessed by counting the tablets consumed, during follow up and at the last visit. It was observed that the patients in both groups A and B consumed $>80 \%$ medication during the study period.

The global efficacy and tolerability assessment by physician and patient in the pooled data is shown in Table 5. The results showed that in the global efficacy assessment

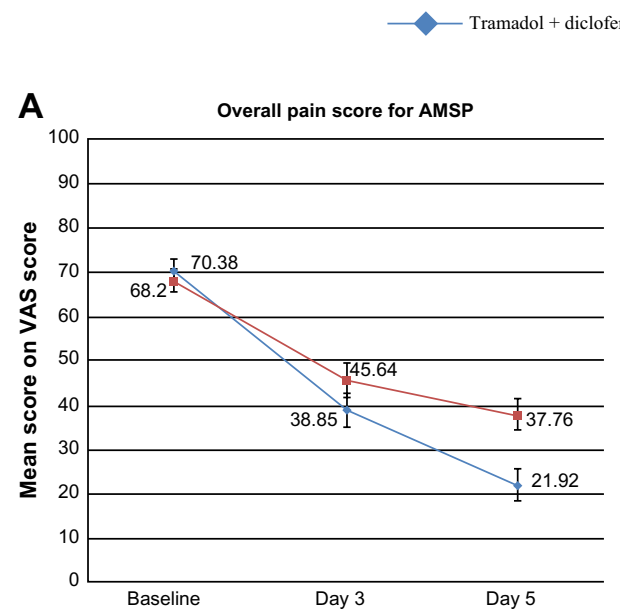

- Tramadol + paracetamol
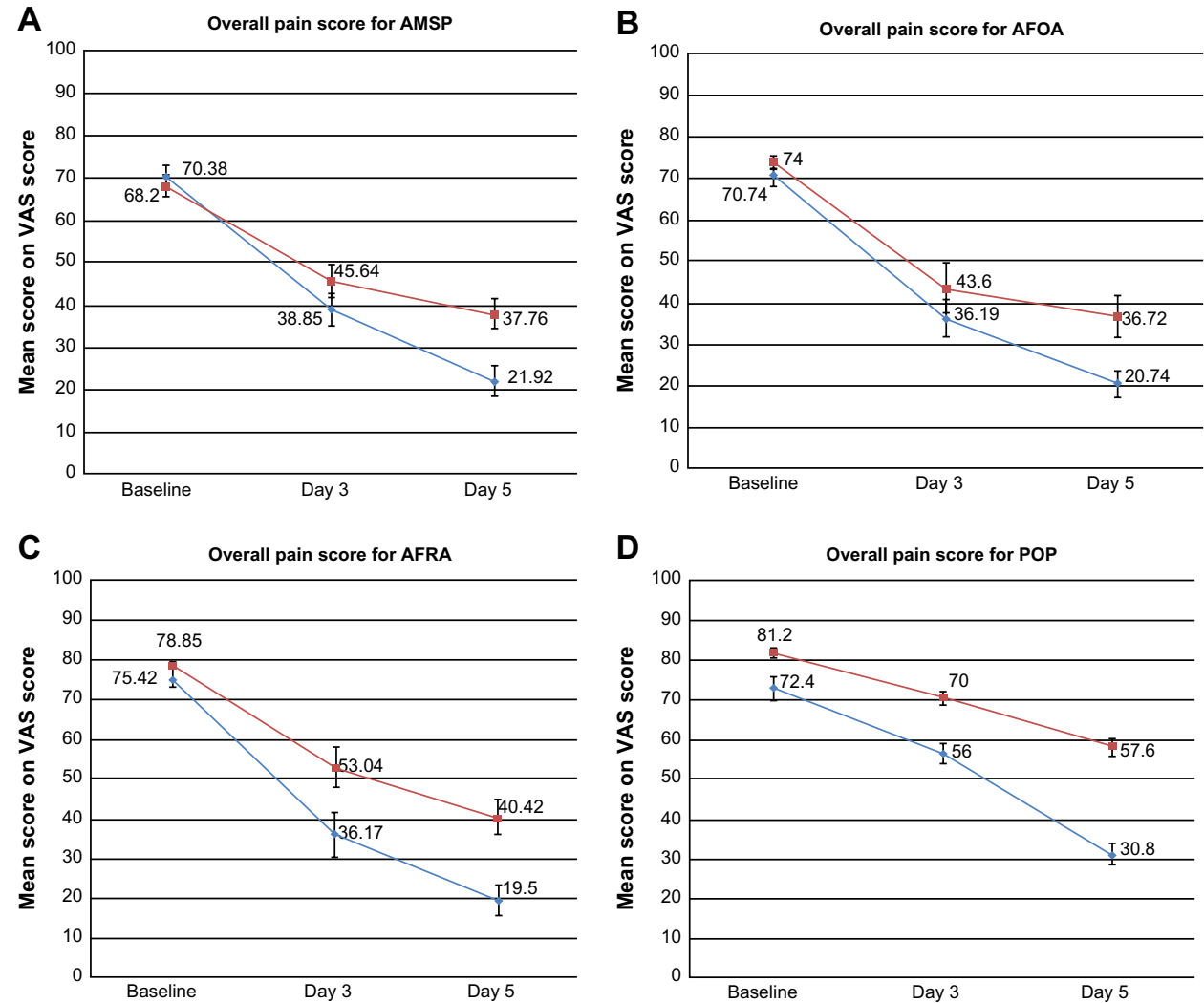

Figure I Comparison of mean VAS score for overall pain, in group A versus group B of the study population.

Notes: (A) Mean score for overall pain in AMSP patients. (B) Mean score for overall pain for AFOA patients. (C) Mean score for overall pain in AFRA patients. (D) Mean score for overall pain in POP patients. The blue line is for group A (tramadol + diclofenac) and the red line is for group B (tramadol + paracetamol).

Abbreviations: AFOA, acute flare of osteoarthritis; AFRA, acute flare of rheumatoid arthritis; AMSP, acute musculoskeletal pain; POP, postoperative pain; VAS, Visual Analog Scale. 
Table 4 Comparison of efficacy parameters between fixed-dose combinations of tramadol-diclofenac and tramadol-paracetamol (pooled data)

\begin{tabular}{|c|c|c|c|}
\hline Efficacy parameters & $\begin{array}{l}\text { Tramadol + diclofenac } \\
(n=102)\end{array}$ & $\begin{array}{l}\text { Tramadol + paracetamol } \\
(n=\mid 0 I)\end{array}$ & $P$-value \\
\hline \multicolumn{4}{|l|}{ Mean VAS score } \\
\hline \multicolumn{4}{|l|}{ For overall pain } \\
\hline Baseline, mean (SEM) & $72.16(13.49)$ & $75.44(10.25)$ & 0.052 \\
\hline Day 3, mean change (\% change) & $-30.44(-42.19)$ & $-22.37(-29.65)$ & 0.001 \\
\hline Day 5 , mean change ( $\%$ change) & $-48.94(-67.83)$ & $-32.34(-42.87)$ & $\begin{array}{l}0.0001 \\
(>95 \%) *\end{array}$ \\
\hline \multicolumn{4}{|l|}{ For pain at rest } \\
\hline Baseline, mean (SEM) & $58.38(12.09)$ & $62.11(10.61)$ & 0.020 \\
\hline Day 3, mean change (\% change) & $-21.30(-36.49)$ & $-18.13(-29.19)$ & 0.171 \\
\hline Day 5, mean change (\% change) & $-43.46(-74.44)$ & $-26.79(-43.14)$ & $\begin{array}{l}0.0001 \\
(>95 \%)^{*}\end{array}$ \\
\hline \multicolumn{4}{|l|}{ For pain on movement } \\
\hline Baseline, mean (SEM) & $76.76(13.23)$ & $79.80(8.90)$ & 0.056 \\
\hline Day 3, mean change (\% change) & $-32.74(-42.64)$ & $-25.09(-31.44)$ & 0.002 \\
\hline Day 5, mean change ( $\%$ change) & $-52.56(-68.47)$ & $-34.68(-43.45)$ & $\begin{array}{l}0.0001 \\
(>95 \%)^{*}\end{array}$ \\
\hline \multicolumn{4}{|l|}{ Mean score for swelling } \\
\hline Baseline, mean (SEM) & $1.88(0.91)$ & $1.84(0.90)$ & 0.805 \\
\hline Day 3, mean change (\% change) & $-0.94(-50.00)$ & $-0.41(-22.32)$ & 0.0001 \\
\hline Day 5, mean change (\% change) & $-1.44(-76.69)$ & $-0.93(-50.57)$ & 0.0001 \\
\hline \multicolumn{4}{|l|}{ Mean score for inflammation } \\
\hline Baseline, mean (SEM) & $1.57(1.02)$ & $\mathrm{I} .4 \mathrm{I}(\mathrm{I} .0 \mathrm{I})$ & 0.317 \\
\hline Day 3, mean change (\% change) & $-0.89(-56.69)$ & $-0.52(-37.04)$ & 0.077 \\
\hline Day 5, mean change ( $\%$ change) & $-1.38(-88.04)$ & $-0.82(-58.10)$ & 0.0001 \\
\hline \multicolumn{4}{|l|}{ Total score for inflammation } \\
\hline Baseline, mean (SEM) & $3.44(1.64)$ & $3.22(1.58)$ & 0.373 \\
\hline Day 3, mean change (\% change) & $-1.83(-53.05)$ & $-0.90(-28.05)$ & 0.0001 \\
\hline Day 5 , mean change (\% change) & $-2.82(-81.99)$ & $-1.75(-54.21)$ & 0.0001 \\
\hline \multicolumn{4}{|c|}{ Rescue medication (diclofenac), no of tablets (number of patients) } \\
\hline Baseline & I (4) & $2(10)$ & \\
\hline Day 3 & $2(3)$ & $2(7)$ & \\
\hline Day 5 & I (2) & $2(5)$ & \\
\hline Total number of tablets $(\%)$ & $8(7.92)$ & $44(43.56)$ & $<0.0001$ \\
\hline Total number of patients, $\mathrm{n}(\%)$ & $9(8.91)$ & $22(21.78)$ & 0.0193 \\
\hline
\end{tabular}

Note: *Power achieved.

Abbreviations: SEM, standard error of the mean; VAS, Visual Analog Scale.

by physicians, approximately $80 \%$ of group A patients and $18 \%$ of group B patients had a very good and excellent grade $(P<0.0001)$, whereas when assessed by patients, $82 \%$ in group A and $16 \%$ in group B had very good and excellent grade $(P<0.0001)$. The global tolerability assessment by physician was good in $77 \%$ of group A and $42 \%$ of group B patients $(P<0.0001)$. The tolerability assessment by patients was also mostly good in both groups (77\% in group A and $40 \%$ in group B) $(P<0.0001)$.

The safety evaluation results are depicted in Table 6. Both the study medication groups had few AEs, among which the common AEs were nausea, vomiting, drowsiness, epigastric pain, and gastritis. The majority of the AEs were mild to moderate in intensity, requiring minimal management, without discontinuation of study drugs. The total number of patients with AEs on day 3 of treatment was significantly less in group A (16) compared with 46 in group B $(P<0.0001)$. The total number of patients with AEs on day 5 of treatment was nine $(8.82 \%)$ in group A and $22(21.78 \%)$ in group B $(P=0.019)$. On both day 3 and day 5 , the most frequent AEs were nausea and vomiting. The laboratory parameters at baseline, day 3, and day 5 showed no significant differences in both the groups.

\section{Discussion}

The combination of diclofenac and tramadol theoretically combines the advantages of the peripherally acting diclofenac at lowest effective dose along with predominantly 
Table 5 Comparison of global efficacy and tolerability assessments in pooled data

\begin{tabular}{|c|c|c|}
\hline Assessments & $\begin{array}{l}\text { Tramadol + } \\
\text { diclofenac } \\
(n=\mid 02)\end{array}$ & $\begin{array}{l}\text { Tramadol + } \\
\text { paracetamol } \\
(n=\mid 0 I)\end{array}$ \\
\hline \multicolumn{3}{|c|}{ Global efficacy assessment by physician ${ }^{\mathrm{a}}$} \\
\hline Poor, n (\%) & $3(2.94)$ & II (10.89) \\
\hline Satisfactory, n (\%) & $5(4.90)$ & $56(55.45)$ \\
\hline Good, n (\%) & $13(12.75)$ & $15(14.85)$ \\
\hline Very good, n (\%) & $45(44.12)$ & $12(11.88)$ \\
\hline Excellent, n (\%) & $36(35.29)$ & $7(6.93)$ \\
\hline \multicolumn{3}{|c|}{ Global efficacy assessment by patient ${ }^{b}$} \\
\hline Poor, n (\%) & $3(2.94)$ & $24(23.76)$ \\
\hline Satisfactory, n (\%) & $3(2.94)$ & $4 \mid(40.59)$ \\
\hline Good, n (\%) & $12(11.76)$ & $19(\mid 8.81)$ \\
\hline Very good, n (\%) & $53(51.96)$ & II (I0.89) \\
\hline Excellent, $\mathrm{n}(\%)$ & $31(30.39)$ & $6(5.94)$ \\
\hline \multicolumn{3}{|c|}{ Global tolerability assessment by physician ${ }^{c}$} \\
\hline Poor, n (\%) & $4(3.92)$ & $23(22.77)$ \\
\hline Moderate, n (\%) & $19(18.63)$ & $36(35.64)$ \\
\hline Good, n (\%) & $79(77.45)$ & $42(4 \mid .58)$ \\
\hline \multicolumn{3}{|c|}{ Global tolerability assessment by patient ${ }^{d}$} \\
\hline Poor, n (\%) & $6(5.88)$ & $33(32.67)$ \\
\hline Moderate, $\mathrm{n}(\%)$ & $17(16.67)$ & $28(27.72)$ \\
\hline Good, n (\%) & $79(77.45)$ & $40(39.60)$ \\
\hline
\end{tabular}

Notes: ${ }^{\mathrm{a}} \chi^{2}=89.87, P<0.0001$; ${ }^{\mathrm{b}} \chi^{2}=98.1, P<0.0001$; ${ }^{\mathrm{c}} \chi^{2}=30.84, P<0.0001$; ${ }^{\mathrm{d}} \chi^{2}=35.15$, $\mathrm{P}<0.0001$.

centrally acting tramadol. Our study was aimed at comparing the safety and efficacy of tramadol and diclofenac with tramadol and paracetamol, as an analgesic agent for moderate to severe pain in musculoskeletal conditions. The present study results indicated that tramadol and diclofenac

Table 6 Comparison of adverse events between group A (tramadol + diclofenac) and group B (tramadol + paracetamol) of study population

\begin{tabular}{|c|c|c|c|}
\hline Adverse events & $\begin{array}{l}\text { Tramadol + } \\
\text { diclofenac } \\
(n=102)\end{array}$ & $\begin{array}{l}\text { Tramadol }+ \\
\text { paracetamol } \\
(n=102)\end{array}$ & $\chi^{2}$ (P-value) \\
\hline \multicolumn{4}{|l|}{ Day 3} \\
\hline Drowsiness, n (\%) & $0(0)$ & I (0.98) & \\
\hline Epigastric pain, n (\%) & I (0.98) & I (0.98) & \\
\hline Gastritis, n (\%) & $3(2.94)$ & $5(4.90)$ & \\
\hline Nausea, n (\%) & $6(5.88)$ & $23(22.55)$ & \\
\hline Vomiting, n (\%) & $6(5.88)$ & $16(15.69)$ & \\
\hline Total events & $16(15.68)$ & $46(45.10)$ & $\begin{array}{l}18.609 \\
(<0.000 \mathrm{I})\end{array}$ \\
\hline \multicolumn{4}{|l|}{ Day 5} \\
\hline Drowsiness, n (\%) & $0(0)$ & $0(0)$ & \\
\hline Epigastric pain, n (\%) & I (0.98) & $2(1.96)$ & \\
\hline Gastritis, n (\%) & $2(1.96)$ & $0(0)$ & \\
\hline Nausea, n (\%) & $4(3.92)$ & $14(13.73)$ & \\
\hline Vomiting, n (\%) & $2(1.96)$ & $6(5.88)$ & \\
\hline Total events & $9(8.82)$ & $22(21.57)$ & $5.478(0.019)$ \\
\hline
\end{tabular}

is the rational combination for management of moderate to severe pain.

The VAS score for overall pain in all the subpopulations was significantly reduced after combination therapy of tramadol and diclofenac. Similarly, in the pooled population, a significant decrease was seen in the VAS score for overall pain, pain at rest, and pain on movement. Interestingly, a previous study employing the FDC of diclofenac and tramadol, ${ }^{19}$ and using an NRS score for evaluation, observed a faster, longer, and homogeneous analgesic effect in patients after unilateral hallux valgus surgery compared with diclofenac alone. Additionally, the combination at all the dose regimens, significantly $(P<0.005)$ improved pain relief and was well tolerated in patients with acute inflammatory pain of moderate to severe intensity. ${ }^{19}$ These findings uphold the result of our study, which differs primarily in terms of the pain score used. Among other related studies, not enough literature is available that explored the effect of similar combinations on the VAS score; however, a meta-analysis of the use of morphine in patients with moderate to severe cancer pain showed that morphine reduced the VAS score to $<30 \mathrm{~mm}$ and also proved that oral morphine had almost similar efficacy to other available opioids..$^{20}$ Another study compared diclofenac-tramadol and diclofenac-paracetamol for pain relief after caesarean section. The results showed a reduction in overall pain score, which was significantly more pronounced in the diclofenac-tramadol group. ${ }^{21}$ The number of rescue analgesic medications consumed was comparable between the two groups (13\% versus $12 \%)(P=0.872) .{ }^{21}$ However, in our study, the amount of rescue medication consumed was greater with tramadol-paracetamol, though the difference was not significant.

A previous study tried to use quantitative testing as a diagnostic test for oxycodone (opioid analgesic) compliance, and this model accurately predicted oxycodone in the urine ( $\pm 10 \%$ for $90 \%$ of the patients). ${ }^{22}$ In our study, compliance with the medication was measured by counting the tablets consumed, during follow up and at the last visit, and our study revealed an overall compliance of $>80 \%$.

The current study showed a significant decrease in the WOMAC index score in AFOA, in the total HAQ score in AFRA, and in the NRS scale assessment for POP. A study on 60 patients with osteoarthritis compared diclofenac versus tramadol in detecting differences in pain relief and functional impairment. The WOMAC score was used, and the study found modestly improved median pain intensity in both treatment groups, with similar improvement in functional parameters. The difference between the two groups was not 
significant. ${ }^{23}$ But as our study observed that the combination of tramadol and diclofenac decreased the WOMAC score, it can be advocated for pain due to osteoarthritis. After 24 hours, the diclofenac and tramadol combination significantly lowered the NRS pain score in comparison with tramadolparacetamol. However, in both the treatment groups, the pain score had reduced only after 2 hours of medication. ${ }^{21}$ The AEs for both the combination drugs occur infrequently and are usually mild to moderate in nature, not warranting discontinuation of therapy. In a previous work, the tramadol and paracetamol combination was compared with only tramadol therapy, for POP following ambulatory hand surgery. The AEs reported were nausea, dizziness, somnolence, vomiting, and increased sweating, and these occurred less frequently with the combination arm $(P=0.004) .{ }^{3}$ The total number of AEs in our study was less in the group receiving the tramadol-diclofenac combination compared with the group receiving the tramadol-paracetamol combination, on both day 3 and day 5 of follow up, and the AEs were mild to moderate in nature, with self-limiting nausea and vomiting being most common.

In response to the findings from the 2012 review of NSAIDs, the UK Medicines and Healthcare Products Regulatory Agency reviewed diclofenac in October 2012 and identified a small increased risk of cardiovascular side effects associated with diclofenac compared with other NSAIDs. ${ }^{24}$ Factors that can affect diclofenac dose include the condition that is being treated. When treating different types of arthritis, such as osteoarthritis or rheumatoid arthritis, the recommended daily dose is $100-150 \mathrm{mg}$ in two or three divided doses. ${ }^{25}$ However, all anti-inflammatory medicines (including NSAIDs and Cyclooxygenase-2 [COX-2] inhibitors) should be used at the lowest possible dose and for the shortest possible period necessary to control symptoms. A physician assessment should consider a patient's need for pain relief and any particular treatment preference they have, as well as any risk factors they may carry.

A limitation of the study was the small sample size due to which the results could not be completely extrapolated to the general population. As well, all patients were suffering from pain due to musculoskeletal conditions (AMSP, POP, AFOA, and AFRA), and hence the study cannot comment on the safety and efficacy of this combination in other clinical conditions. Further, this was a clinical trial set up in a controlled setting, where the role of comorbidities and concomitant medications could not be evaluated completely to generate further evidence, thereby warranting a study in a real-world setting.

\section{Conclusion}

The tramadol-diclofenac combination showed a significantly greater reduction in VAS scores for pain, and in swelling and inflammation, among patients with AMSP, POP, AFOA, and AFRA as compared with the tramadol-paracetamol combination. The WOMAC and HAQ scores in patients with AFOA and AFRA, respectively, showed a consistent decrease on day 3 and day 5 of therapy with the tramadol-diclofenac combination. This drug combination also influenced the pain intensity measured by NRS score for POP, as early as 2 hours after consumption of medication. The side effects for both combinations were comparable, were usually mild to moderate in nature, and occurred infrequently, not warranting discontinuation of therapy. Larger trials in special populations, such as geriatric patients, cancer patients, etc, may be needed to further substantiate the findings of the present study.

\section{Acknowledgments}

The authors acknowledge Abbott Healthcare Pvt Ltd for providing financial support along with the study drug Durapain $^{\circledR}$ (tramadol $50 \mathrm{mg}$ and diclofenac $75 \mathrm{mg}$ ) for the project. The authors also acknowledge the contribution of Clinsearch Healthcare Solutions Pvt Ltd, India, for assistance with study design, data collection, and data analysis, and the contribution of Tech Observer, India, for assistance with manuscript preparation.

\section{Disclosure}

Financial support for the project, along with the study drug, Durapain $^{\circledR}$ (tramadol $50 \mathrm{mg}$ and diclofenac $75 \mathrm{mg}$ ), was provided by Abbott Healthcare Pvt Ltd, India. S Biswas, M Gabhane, M Naik, and K Patel are employees of Abbott Healthcare Pvt Ltd, India. The other authors report no conflicts of interest.

\section{References}

1. Connors AF Jr, Dawson NV, Desbiens NA, et al. A controlled trial to improve care for seriously ill hospitalized patients. The study to understand prognoses and preferences for outcomes and risks of treatments (SUPPORT). The SUPPORT Principal Investigators. JAMA. 1995;274(20):1591-1598.

2. Vanderah TW. Pathophysiology of pain. Med Clin North Am. 2007; 91(1):1-12

3. Rawal N, Macquaire V, Catalá E, Berti M, Costa R, Wietlisbach M. Tramadol/paracetamol combination tablet for postoperative pain following ambulatory hand surgery: a double-blind, double-dummy, randomized, parallel-group trial. J Pain Res. 2011;4:103-110.

4. Raffa RB. Pharmacology of oral combination analgesics: rational therapy for pain. J Clin Pharm Ther. 2001;26(4):257-264.

5. who.int [homepage on the Internet]. WHO's cancer pain ladder for adults. World Health Organization; 2012 [cited July 28, 2013]. Available from: http://www.who.int/cancer/palliative/painladder/en/. Accessed June 27, 2014 
6. Leung L. From ladder to platform: a new concept for pain management. J Prim Health Care. 2012;4(3):254-258.

7. McCarberg B, Tenzer P. Complexities in the pharmacologic management of osteoarthritis pain. Curr Med Res Opin. 2013;29(5):539-548.

8. Mercadante $\mathrm{S}$. The use of anti-inflammatory drugs in cancer pain. Cancer Treat Rev. 2001;27(1):51-61.

9. Schug SA. The role of tramadol in current treatment strategies for musculoskeletal pain. Ther Clin Risk Manag. 2007;3(5):717-723.

10. Brunton LL, Chabner BA, Knollmann BC. Goodman and Gilman's The Pharmacological Basis of Therapeutics. 12th ed. New York, NY: McGraw Hill; 2011.

11. Filitz J, Ihmsen H, Günther W, et al. Supra-additive effects of tramadol and acetaminophen in a human pain model. Pain. 2008;136(3): 262-270.

12. McQuay H, Edwards J. Meta-analysis of single dose oral tramadol plus acetaminophen in acute postoperative pain. Eur J Anaesthesiol Suppl. 2003;28:19-22.

13. Gan TJ. Diclofenac: an update on its mechanism of action and safety profile. Curr Med Res Opin. 2010;26(7):1715-1731.

14. Raffa RB, Friderichs E, Reimann W, Shank RP, Codd EE, Vaught JL. Opioid and nonopioid components independently contribute to the mechanism of action of tramadol, an 'atypical' opioid analgesic. J Pharmacol Exp Ther. 1992;260(1):275-285.

15. Australian and New Zealand College of Anaesthetists (ANZCA). Acute Pain Management: Scientific Evidence. 2nd ed. Melbourne: Australian and New Zealand College of Anaesthetists; 2005.

16. Hawker GA, Mian S, Kendzerska T, French M. Measures of adult pain: Visual Analog Scale for Pain (VAS Pain), Numeric Rating Scale for Pain (NRS Pain), McGill Pain Questionnaire (MPQ), Short-Form McGill Pain Questionnaire (SF-MPQ), Chronic Pain Grade Scale (CPGS), Short Form-36 Bodily Pain Scale (SF-36 BPS), and Measure of Intermittent and Constant Osteoarthritis Pain (ICOAP). Arthritis Care Res. 2011;63(S11):S240-S252.

17. Western Ontario and McMaster Universities Osteoarthritis Index (WOMAC) [webpage on the internet]. American College of Rheumatology Research Committee; 2012. Available from: https:// www.rheumatology.org/Practice/Clinical/Clinicianresearchers/ Outcomes_Instrumentation/Western_Ontario_and_McMaster_Universities_Osteoarthritis_Index_(WOMAC)/. Accessed July 23, 2014.
18. IMACS Form 04a: Instructions for the Health Assessment Questionnaire. Available from: https://www.niehs.nih.gov/research/resources/ assets/docs/haq_instructions.pdf. Accessed July 23, 2014.

19. Auad A, Cadena L, Garzón LA, et al. Efficacy and safety of the fixed combination diclofenac/tramadol in acute pain: randomized clinical trial phase III, double-blind, controlled. Iberoamericana Rev Pain. 2009;4:13-23.

20. Wiffen PJ, Wee B, Moore RA. Oral morphine for cancer pain. Cochrane Database Syst Rev. 2013;7:CD003868.

21. Mitra S, Khandelwal P, Sehgal A. Diclofenac-tramadol vs diclofenacacetaminophen combinations for pain relief after caesarean section. Acta Anaesthesiol Scand. 2012;56(6):706-711.

22. Linares OA, Daly D, Stefanovski D, Boston RC. A new model for using quantitative urine testing as a diagnostic tool for oxycodone treatment and compliance. J Pain Palliat Care Pharmacother. 2013;27(3):244-254.

23. Pavelka K, Pelisková Z, Stehlíková H, Ratcliffe S, Repas C Intraindividual differences in pain relief and functional improvement in osteoarthritis with diclofenac or tramadol. Clin Drug Investig. 1998;16(6):421-429.

24. European Medicines Agency. New safety advice for diclofenac - CMDh endorses PRAC recommendation [press release]. London: European Medicines Agency; June 28, 2013. Available from: http://www.ema. europa.eu/ema/index.jsp?curl=pages/news_and_events/news/2013/06/ news_detail_001830.jsp\&mid=WC0b01ac058004d5c1. Accessed March 25, 2014.

25. Medicines.org.uk [homepage on the Internet]. SPC. Diclofenac potassium $50 \mathrm{mg}$ tablets. electronic Medicines Compendium (eMC) (Datapharm); 2011 [updated January 17, 2014; cited June 19, 2014]. Available from: http://www.medicines.org.uk/emc/medicine/24377/ spc\#INDICATIONS. Accessed June 27, 2014.
Journal of Pain Research

\section{Publish your work in this journal}

The Journal of Pain Research is an international, peer-reviewed, open access, online journal that welcomes laboratory and clinical findings in the fields of pain research and the prevention and management of pain. Original research, reviews, symposium reports, hypothesis formation and commentaries are all considered for publication.

\section{Dovepress}

The manuscript management system is completely online and includes a very quick and fair peer-review system, which is all easy to use. Visit http://www.dovepress.com/testimonials.php to read real quotes from published authors. 